\title{
PREDIKSI STRUKTUR BAWAH PERMUKAAN GUNUNG GUNTUR BERDASARKAN DATA PENGAMATAN GAYABERAT
}

\section{Tedy Y. Pusdiono 1), Hasanuddin Z. Abidin ${ }^{1}$, Wawan G.A. Kadir ${ }^{2}$ ), Kosasih Prijatna'), Kajuro Nakamura ${ }^{3}$ ), Kiyoshi Ito ${ }^{3}$ )}

\author{
1) Jurusan Teknik Geodesi, Institut Teknologi Bandung \\ Jl. Ganesha 10, Bandung 40132 \\ 2) Jurusan Teknik Geofisika, Institut Teknologi Bandung \\ 3) RCEP DPRI Kyoto University Japan
}

\begin{abstract}
ABSTRAK
Metode gayaberat secara terestris dapat diterapkan untuk kegiatan pemantauan aktivitas gunungapi, yaitu melalui prediksi dan interpretasi struktur bawah permukaannya (sub surface structure) yang diperoleh berdasarkan pemodelan dari nilai anomali gayaberatnya, baik anomali Bouguer atau anomali residualnya.

Makalah ini membahas mengenai penerapan metode gayaberat secara terestris dalam kegiatan pemantauan aktivitas gunungapi, dengan menggunakan Gravimeter LaCoste and Romberg model G-605 dan GPS tipe geodetik dua-frekuensi. Lokasi daerah penelitian adalah Gunung Guntur di Kabupaten Garut. Data pengamatan gayaberat yang diolah hingga diperoleh nilai anomalinya, kemudian dilakukan pemodelan dan interpretasi mengenai struktur bawah permukaannya. Hasil interpretasi manunjukkan bahwa terdapat pemunculan beberapa intrusi magma di komplek Gunung Guntur, yaitu di sekitar puncak Guntur, Kabuyutan, Parukuyan, Masigit, dan juga Kawah Kamojang.
\end{abstract}

\section{PENDAHULUAN}

Gunung Guntur merupakan salah satu gunung api diantara 17 gunungapi aktif di Jawa Barat. Berdasarkan aktivitasnya, Gunung Guntur semenjak tahun 1690 sampai tahun 1847 memiliki catatan masa kegiatan (letusan-letusan) sebanyak 22 kali. Beberapa tahun belakangan ini Gunung Guntur mulai menunjukkan aktivitasnya lagi setelah selama 153 tahun menjalani masa diamnya. Upaya preventif terhadap kemungkinan terjadinya letusan yang dapat menimbulkan bahaya, antara lain dengan melakukan pemantauan aktivitas gunung tersebut baik secara kontinyu maupun periodik.

Salah satu kegiatan pemantauan aktivitas gunungapi tersebut adalah dengan metode gaya berat. Kegiatan pengamatan gayaberat yang dilakukan atas kerjasama Jurusan Teknik Geodesi ITB, Direktorat Vulkanologi dan Mitigasi Bencana Geologi, dan Disaster Prevention Research Institute (DPRI), Universitas Kyoto Jepang.

\section{PENGAMATAN GAYABERAT DI GUNUNG GUNTUR}

Metode gaya berat yang dilakukan adalah dengan metode pengamatan relatif (relative measurements) menggunakan gravimeter tipe geodetik, Lacoste-Romberg model G605 sedangkan posisi titik-titik stasion gayaberat ditentukan dengan metode penentuan posisi teliti (precise positioning) menggunakan GPS tipe geodetik dua-frekuensi merk Leica System 300.

Lokasi daerah penelitian adalah Gunung Guntur dan sekitarnya, yaitu pada wilayah $107^{\circ} 45^{\prime} \mathrm{T}-107^{\circ} 55^{\prime} \mathrm{T}$ dan $7^{\circ} 2^{\prime} \mathrm{S}-7^{\circ} 12^{\prime} \mathrm{S}$. Pengamatan gayaberat dilakukan pada 297 titik, diikatkan ke jaring gayaberat standar internasional (IGSN71) yang terdapat di Direktorat Geologi Bandung (titik DG.0) untuk memperoleh nilai gayaberat relatifnya. 
Nilai gayaberat di titik DG.0 berdasarkan pengamatan tahun 1996 (Nakamura, 1997) adalah sebesar $977976.515 \mathrm{mGal}$.

Penentuan posisi dengan Global Positioning System (GPS) menggunakan metode statik singkat (rapid static), yaitu antara 150-200 epoch atau 5-10 menit di setiap titiknya, dan pegamatan gayaberat dilakukan selama 5-10 menit.

\section{PENGOlahan DATA}

Pengolahan data GPS dilakukan dengan menggunakan software dari Leica Geosystem, yaitu SKI Static Kinematics Software versi 2.3, yang dapat menghasilkan ketelitian koordinat relatif pada level beberapa $\mathrm{cm}$. Posisi stasion pengamatan gayaberat dihitung secara differensial dengan diikatkan secara relatif ke titik pemantauan deformasi Gunung Guntur yang berada di depan pos pengamatan Gunung Guntur (stasion POS GUNTUR).

Pada pengolahan data ini metode baseline yang dipergunakan adalah radial dengan panjang maksimal 20 kilometer dan memiliki tingkat presisi sekitar beberapa mm Model troposfer yang dipergunakan adalah Hopfield (Hofmann-Wellenhof et al., 1992), dan model ionosfernya menggunakan model standar, yaitu menggunakan kombinasi linier dari frekuensi gelombang pembawa L1 dan L2, untuk menghilangkan efek bias yang disebabkan oleh refraksi ionosfir.

Posisi geodetik yang dihasilkan oleh GPS diberikan dalam datum World Geodetic System 1984 (WGS 84), dan oleh karena itu peta topografi dan model permukaan dijital yang akan dipergunakan dalam koreksi nilai gayaberat juga disesuaikan dengan melakukan transformasi koordinat.

Pada makalah ini peta topografi yang dipergunakan untuk membuat model permukaan dijital, awalnya memiliki datum Jakarta dengan ellipsod referensi Bessel 1841. Dijitasi dilakukan secara manual dengan memasukkan data koordinat dan tinggi $(N, E, h)$ dari titik-titik yang mewakili bentuk-bentuk penting, seperti puncak gunung/bukit, lembah, titik triangulasi, dan lain-lain. Proses tranformasi koordinat dilakukan dengan menggunakan perangkat lunak Geographic Calculator versi 3.08, dari Blue Marble Geographics, dimana parameter translasi datum Jakarta terhadap WGS 84 didefinisikan sebagai berikut:

$$
\begin{array}{lll}
\mathrm{dX} & : & -377.000 \mathrm{~m} \\
\mathrm{dY} & : & 681.000 \mathrm{~m} \\
\mathrm{dZ} & : & -50.000 \mathrm{~m}
\end{array}
$$

Dalam pengolahan data gayaberat, tahapan yang digunakan adalah sebagai berikut :

1. Penentuan nilai gayaberat relatif tiap stasion, yang meliputi : konversi bacaan gravimeter ke satuan mGal, koreksi pasang surut bumi (tidal), koreksi drift alat, dan menghitung nilai gayaberat relatif tiap titiik terhadap IGSN71 (titik DG.0)

2. Penentuan nilai gayaberat normal tiap titik gayaberat.

3. Menghitung nilai Anomali Bouguer lengkap, yang meliputi : koreksi bebas udara (free air), Bouguer, dan topografi.

4. Melakukan estimasi rapat massa untuk memperoleh nilai rapat massa yang optimum dengan metode Nettleton.

5. Membuat pemodelan untuk interpretasi kualitatif maupun kuantitatif mengenai struktur bawah permukaan daerah penelitian dengan metode pemodelan kedepan (forward modeling).

Dalam hal ini nilai gayaberat normal dihitung berdasarkan WGS84 Ellipsoidal Gravity Formula (Untung dan Suharyono, 1998) yaitu : 


$$
\gamma=97803267714\left(\frac{1+0.00193185186513 \sin ^{2} \phi}{\sqrt{\left(1-0.006694379013 \sin ^{2} \phi\right)}}\right)
$$

dimana $\phi$ adalah lintang dari lokasi yang bersangkutan.

Koreksi bebas udara (free air), KBU, dihitung dengan persamaan:

$$
K B U=0.3086 h
$$

dan koreksi Bouguer (KB) dihitung dengan persamaan:

$$
K B=0,04192 \rho h
$$

dimana $\rho$ adalah densitas massa dan $\mathrm{h}$ adalah tinggi dari lokasi yang bersangkutan.

Koreksi topografi (KT) dihitung dengan menggunakan tabel Hammer (Hammer chart). Tabel Hammer dihitung berdasarkan persamaan (4) yang disesuaikan dengan peta topografi yang telah didijitasi, yaitu :

$$
K T=G \rho \varphi\left(r_{o}-r_{i}+\sqrt{\left(r_{i}^{2}+h^{2}\right)}-\sqrt{\left(r_{o}^{2}+h^{2}\right)}\right.
$$

Nilai Anomali Bouguer lengkapnya kemudian dihitung dengan persamaan berikut:

$$
A B=g_{\text {relatif }}-(\gamma-K B U+K B-K T)
$$

Estimasi rapat massa dilakukan dengan metode Nettleton pada tiga lintasan yang memiliki bentuk topografi yang kasar dan tidak terdapat anomali gayaberat target (Kadir, 1998), lintasan 1, 2, dan 3 pada gambar 1a. Estimasi rapat massa dilakukan dengan cara grafis dan numeris, yaitu dengan menganalisis korelasi silang dari nilai anomali bouguer, elevasi topografi, dan nilai gayaberat pengamatannya. Besarnya nilai korelasi silang tersebut dihitung dengan persamaan:

$$
k=\frac{\sum_{i=1}^{n} \Delta g_{i} h_{i}}{\sum_{i=1}^{n} h_{i}{ }^{2}}
$$

\begin{tabular}{|c|c|c|c|c|c|c|c|c|c|}
\hline & $\begin{array}{c}\rho \\
\left(\mathrm{gr} / \mathrm{cm}^{3}\right)\end{array}$ & 1.800 & 2.000 & 2.210 & 2.400 & 2.610 & 2.670 & 2.900 & 2.990 \\
\hline \multirow{3}{*}{ 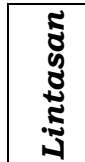 } & 1 & 0.041 & 0.033 & 0.024 & 0.016 & 0.008 & 0.005 & -0.004 & -0.008 \\
\hline & 2 & 0.049 & 0.041 & 0.032 & 0.024 & 0.015 & 0.013 & 0.004 & 0.000 \\
\hline & 3 & 0.043 & 0.035 & 0.026 & 0.018 & 0.010 & 0.007 & -0.002 & -0.006 \\
\hline
\end{tabular}

Contoh penampang lintasan untuk estimasi rapat massa ditunjukkan oleh gambar $1 \mathrm{~b}$ lintasan 1), yang hasilnya diberikan pada Tabel 1 berikut.

Tabel 1. Hasil estimasi rapat massa metode Nettleton.

Rapat massa optimum di seluruh lintasan hasil perhitungan dengan metode Nettleton yang dipilih adalah $2.67 \mathrm{gr} / \mathrm{cm}^{3}$. 


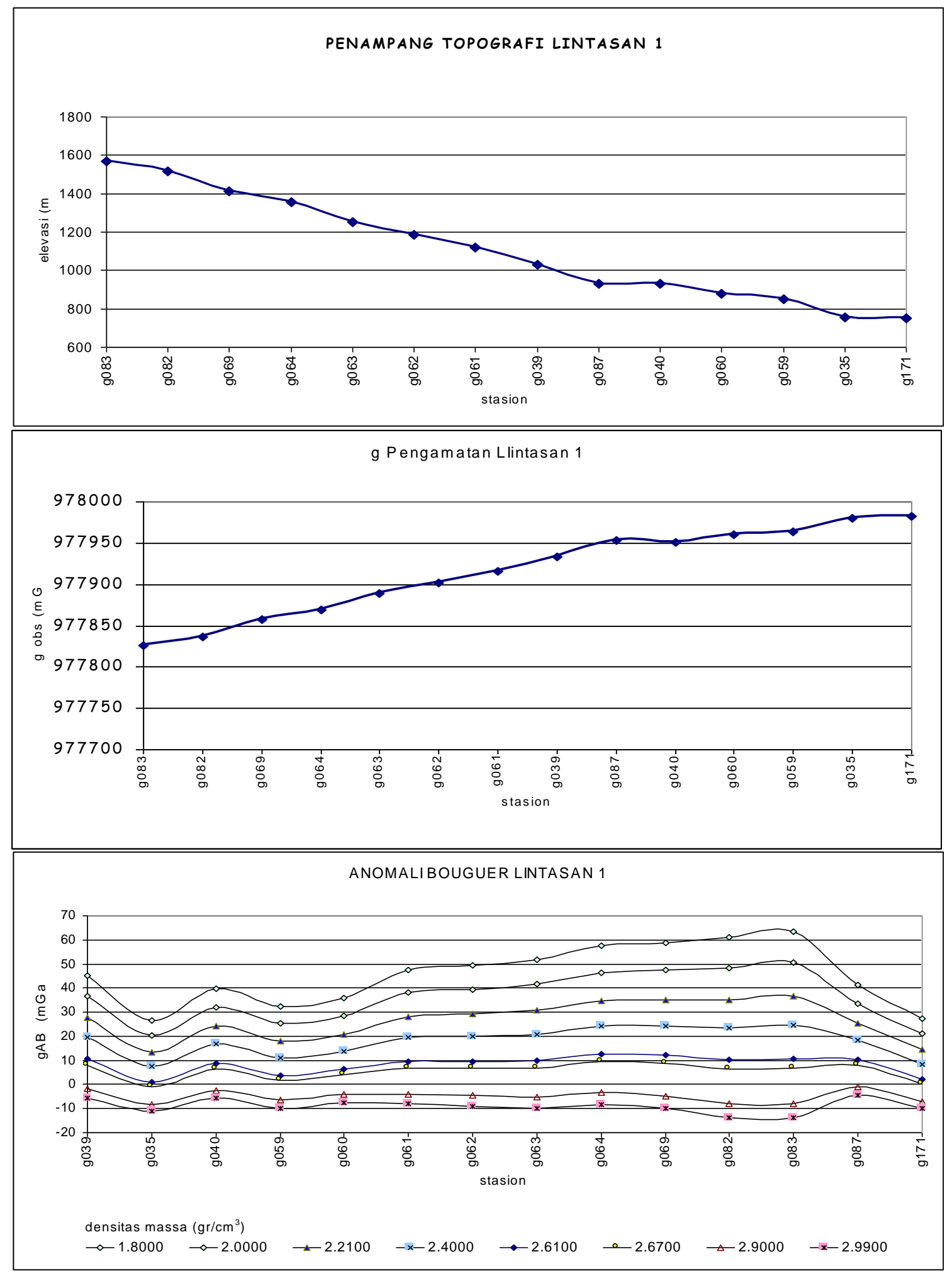

Gambar 1. Penampang lintasan 1 pemodelan. 


\section{PEMODELAN DAN INTERPRETASI}

Sebelum pemodelan dan interpretasi dilakukan proses pemisahan Anomali Bouguer lengkap dari pengaruh regionalnya (filtering) dilakukan dengan menggunakan metode polinomial orde 3. Pemodelan struktur bawah permukaan menggunkan metode forward modeling pada lintasan penampang yang memiliki perbedaan nilai anomali Bouguer sisa (residual) yang cukup besar.

Interpretasi mengenai struktur bawah permukaan Gunung Guntur dilakukan dengan cara kuantitatif dan kualitatif. Interpretasi kuantitatif dilakukan dengan metode forward modeling, dan menggunakan hitungan metode Talwani dalam program Interactive Gravity Interpretation, "GRIN", yang dikembangkan oleh Richard Almond tahun 1986. Interpretasi kuantitatif metode forward modeling ini dapat memberikan hasil yang beragam, oleh karena itu perlu melakukan validasi dengan cara membandingkannya terhadap data atau informasi penunjang, seperti struktur geologi permukaan dari peta geologi, peta anomali bouguer dalam wilayah yang lebih luas dari daerah penelitian, dan lain-lain. Interpretasi kualitatif dilakukan dengan membaca pola kontur pada peta anomali residual (lihat Gambar 2 s/d 4).

Peta anomali residual memperlihatkan bahwa terdapat pola kontur dengan harga anomali rendah dan cukup tinggi. Kontur anomali rendah terdapat di sekitar puncak Gunung Guntur, Parukuyan, dan Masigit, di sekitar kota Garut, di sekitar kecamatan Kadungora, dan di sekitar Gunung Pulus, sebelah utara komplek Guntur. Hal ini diprediksikan sebagai adanya sesar yang mengalami penurunan (graben) dan adanya perubahan suhu batuan menjadi lebih panas akibat adanya intrusi magma di bawahnya. Sedangkan nilai anomali yang cukup tinggi hampir tersebar secara merata di seluruh daerah penelitian. Berdasarkan nilai anomali ini diprediksikan bahwa daerah penelitian memiliki struktur batuan yang relatif homogen.

Hasil interpretasi dan prediksi struktur bawah permukaan Gunung Guntur di tunjukkan pada Gambar-Gambar 2, 3 dan 4. Lintasan-lintasan penampang pemodelan yang dipilih memiliki arah Barat laut-Tenggara (lintasan A-B), Utara-Selatan (lintasan CD), dan Barat - Timur (lintasan E-F).

Gambar 2 menunjukkan bahwa hasil interpretasi dan prediksi lintasan A - B yang melewati Gunung Gandapura, Masigit, dan Guntur, adalah sebagai berikut :

1. Poligon kontras rapat massa $-0.75 \mathrm{gr} / \mathrm{cm} 3$, diprediksikan sebagai lapisan endapan hasil erupsi terakhir Gunung Guntur

2. Poligon kontras rapat massa $-0.25 \mathrm{gr} / \mathrm{cm} 3$, diprediksikan sebagai lapisan sedimen hasil erupsi Gunung Guntur yang lebih tua dari poligon no. 1

3. Poligon kontras rapat massa $-0.15 \mathrm{gr} / \mathrm{cm} 3$, diprediksikan sebagai lapisan sedimen erupsi hasil Gunung Gandapura.

4. Poligon kontras rapat massa $-0.06 \mathrm{gr} / \mathrm{cm} 3$, diprediksikan sebagai lapisan batuan terluar penyusun komplek Gunung Guntur

5. Poligon kontras rapat massa $0.00 \mathrm{gr} / \mathrm{cm} 3$, diprediksikan sebagai lapisan basemen.

6. Poligon Kontras rapat massa $0.23 \mathrm{gr} / \mathrm{cm} 3$, dipredisksikan sebagai intrusi magma yang berusia muda dan merupakan pergerakan intrusi yang berasal dari bawah kaldera Gandapura yang merupakan kaldera tua ke arah tenggara.

Gambar 3 menunjukkan hasil interpretasi dan prediksi lintasan C - D yang melewati kota Garut, Leles, dan Kadungora, yaitu sebagai berikut :

1. Poligon kontras rapat massa $-0.25 \mathrm{gr} / \mathrm{cm} 3$, diprediksikan sebagai lapisan sedimen hasil erupsi Gunung Guntur

2. Poligon kontras rapat massa $-0.15 \mathrm{gr} / \mathrm{cm} 3$, diprediksikan sebagai lapisan sedimen hasil erupsi Gunung Gandapura yang telah mengalami proses erosi. 
3. Poligon kontras rapat massa $-0.06 \mathrm{gr} / \mathrm{cm} 3$, diprediksikan sebagai lapisan batuan terluar penyusun komplek Gunung Guntur.

4. Poligon kontras rapat massa $0.00 \mathrm{gr} / \mathrm{cm} 3$, diprediksikan sebagai lapisan basemen.

5. Poligon kontras rapat massa $0.25 \mathrm{gr} / \mathrm{cm} 3$, diprediksikan sebagai intrusi magma yang terjadi di sebelah timur dan timur laut Gunung Guntur.

Gambar 4 menunjukkan hasil interpretasi dan prediksi lintasan E - F yang melewati Kawah Kamojang dan Puncak Gunung Guntur, yaitu sebagai berikut :

1. Poligon kontras rapat massa $-0.75 \mathrm{gr} / \mathrm{cm} 3$, diprediksikan sebagai lapisan endapan hasil erupsi terakhir Gunung Guntur

2. Poligon kontras rapat massa $-0.25 \mathrm{gr} / \mathrm{cm} 3$, diprediksikan sebagai lapisan sedimen hasil erupsi Gunung Guntur yang lebih tua dari poligon no. 1

3. Poligon kontras rapat massa $-0.15 \mathrm{gr} / \mathrm{cm} 3$, diprediksikan sebagai lapisan sedimen erupsi hasil Gunung Gandapura.

4. Poligon kontras rapat massa $-0.06 \mathrm{gr} / \mathrm{cm} 3$, diprediksikan sebagai lapisan batuan terluar penyusun komplek Gunung Guntur

5. Poligon kontras rapat massa $0.00 \mathrm{gr} / \mathrm{cm} 3$, diprediksikan sebagai lapisan basemen.

6. Poligon Kontras rapat massa $0.23 \mathrm{gr} / \mathrm{cm} 3$, dipredisksikan sebagai intrusi magma dengan kedalaman yang cukup dangkal, yaitu sekitar 2 kilometer dari permukaan

\section{KESIMPULAN}

Hasil prediksi dan interpretasi dari data anomali gayaberat menunjukkan terdapat pemunculan intrusi di beberapa tempat dalam komplek Gunung Guntur yang diduga berhubungan dengan deretan magma dan disekitar Kawah Kamojang, juga terdapat sesar turun di sekitar puncak Gunung Guntur, Kabuyutan, Parukuyan, dan Masigit yang terjadi akibat adanya intrusi magma di bawahnya.

Pengamatan gayaberat yang telah dilakukan masih menunjukkan adanya kekurangan data di beberapa tempat, oleh karena itu perlu adanya pengamatan tambahan untuk merapatkan data yang telah diperoleh, sehingga dapat diketahui apakah terdapat benda anomali yang lain di daerah sekitar puncak komplek Gunung Guntur, Gunung Gandapura dan Kawah Kamojang. Disamping itu untuk menunjang kegiatan pemantauan deformasi Gunung Guntur, implementasi metode gayaberat ini sebaiknya ditunjang dengan metode geodetik serta geofisika lainnya, seperti survey seismik, geolistrik, dan geokimia. 


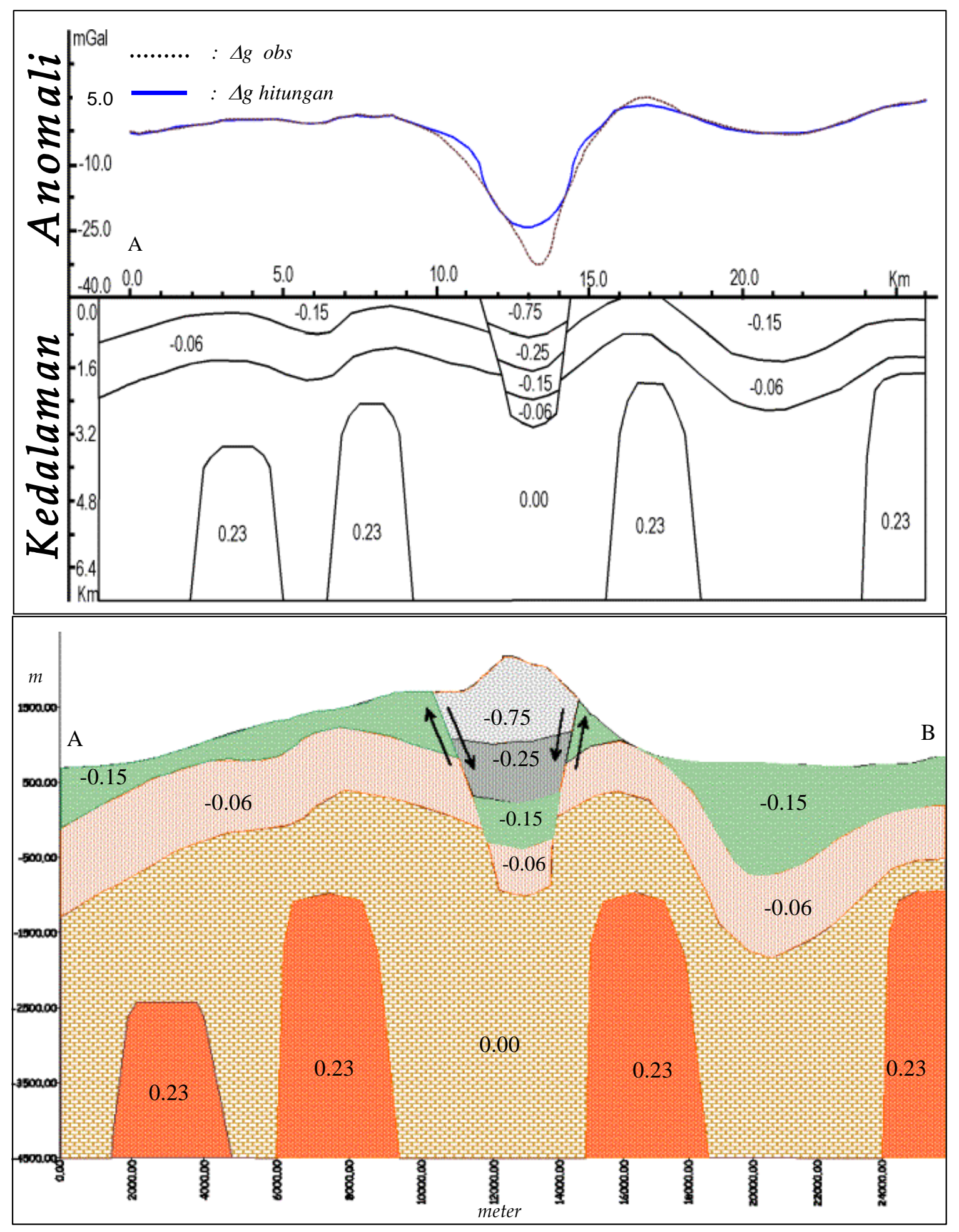

Gambar 2. Prediksi dan Interpretasi Struktur Bawah Permukaan Gunung Guntur Penampang Lintasan A - B (Arah Barat Laut - Tenggara) 


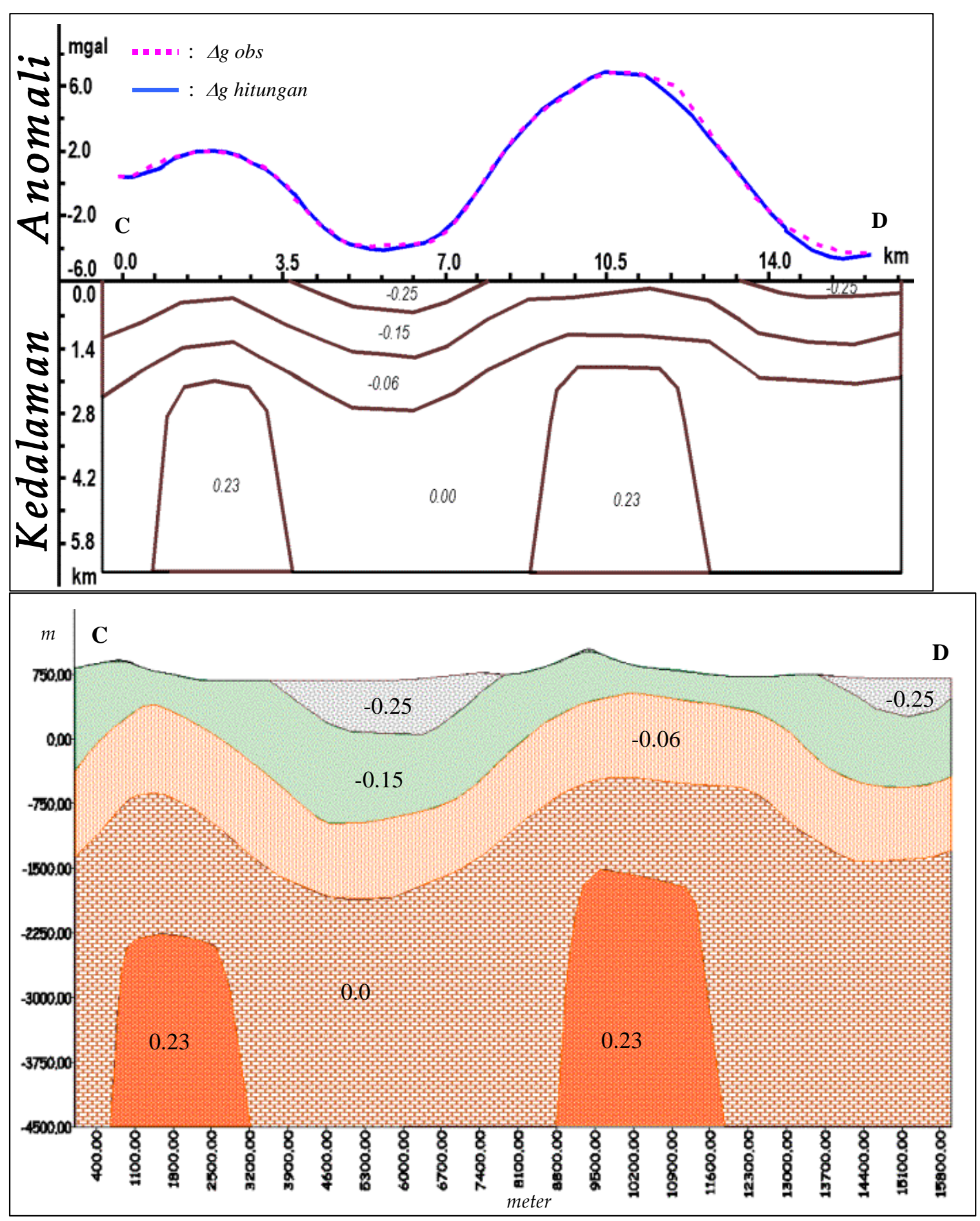

Gambar 3. Prediksi dan Interpretasi Struktur Bawah Permukaan Gunung Guntur Penampang Lintasan C - D ( Arah Utara - Selatan) 

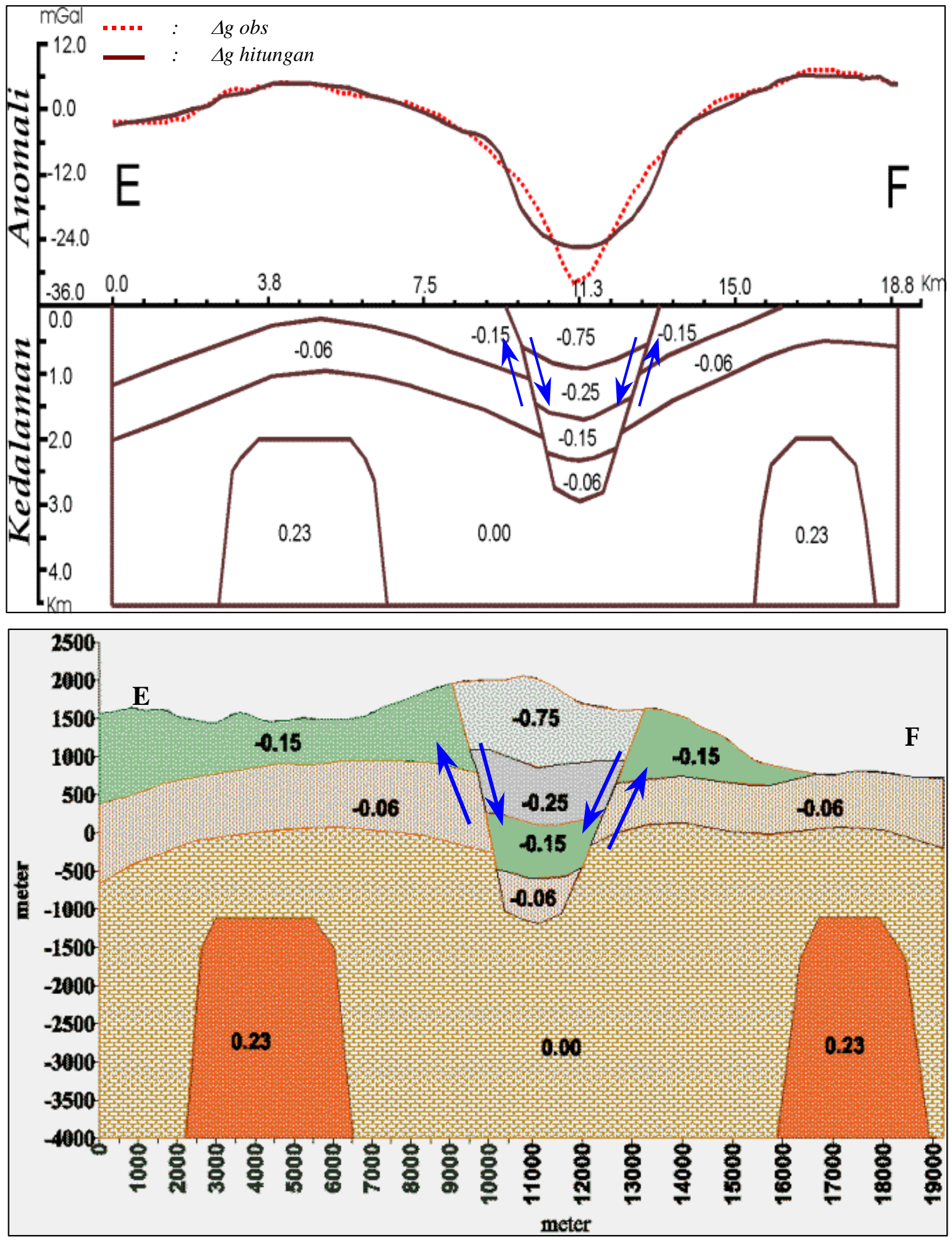

Gambar 4. Prediksi dan Interpretasi Struktur Bawah Permukaan Gunung Guntur Penampang Lintasan E - F (Arah Barat - Timur) 


\section{DAFTAR REFERENSI}

Abidin, H.Z. (1995). Penentuan Posisi dengan GPS dan aplikasinya, PT Pradnya Paramita, Jakarta, 110 halaman.

Heiskanen, W.A., dan Moritz, H. (1967) Physical Geodesy, W.H. Freeman and Company, San Francisco, 364 halaman.

Hofmann-Wellenhof, B., dkk. (1992) GPS Theory and Practice, Springer-Verlag Wien, New York.

Kadir, W.G.A. (1998) Diktat Kuliah Eksplorasi Gayaberat dan Magnetik (TG332) Jurusan Teknik Geofisika, Fakultas Teknologi Mineral, ITB.

Kartijoso, S. (1991) G. Guntur, Berita Berkala Vulkanologi No.169, edisi khusus, Direktorat Vulkanologi, Departemen Pertambangan dan Energi Republik Indonesia, halaman 2-6.

Matahelumual, J. (1989) G. Guntur, Berita Berkala Vulkanologi No.120, edisi khusus, Direktorat Vulkanologi, Departemen Pertambangan dan Energi Republik Indonesia, halaman 16-26.

Nakamura, Kajuro. (1997) Gravity Measurements around the Lembang and Cimandiri Faults, International Symposium on Natural Disaster Prediction and Mitigation, Kyoto, Japan, Desember 1997, halaman 202.

Nakamura, Kajuro., dkk. (1998) Gravity Survey Crossing the Lembang and the Cimandiri Fault, Symposium on Japan-Indonesia IDNDR Project, Bandung, September 1998, Indonesia, halaman 215-221

Suantika, G., dkk. Characteristic of Volcanic Earthquakes around Guntur Volcano, West Java, Indonesia, Symposium on Japan-Indonesia IDNDR Project, Bandung, September 1998, Indonesia, halaman 71-80.

Surmayadi, M., dkk. (1998) Peta Geologi Gunungapi Guntur Jawa Barat, Direktorat Vulkanologi, Departemen Pertambangan dan Energi Republik Indonesia.

Sutawidjaya, I.S., dkk (1996) Laporan Evaluasi Kegiatan G. Guntur Jawa Barat, Proyek Mitigasi Bencana Geologi, No.63/DV/97, Direktorat Vulkanologi, Departemen Pertambangan dan Energi Republik Indonesia, 13 halaman.

Telford, W.M., dkk. (1990) Applied Geophysics second edition, Cambridge University Press, New York, USA.

Torge, W.M. (1980) Geodesy, an introduction, Walter de Gruyter, Berlin, Germany, 254 halaman.

Tsuboi, Chuji. (1983). Gravity, George Allen and Unwin Ltd., London, 254 halaman.

Untung, M. dan Suharyono, S. (1998). "Data gaya berat dan penafsirannya", dalam: Penerapan metode geofisika di Indonesia 1977-1997, edisi pertama, HAGI, Penerbit ITB, Bandung, hal. 13-20. 